\title{
Níveis de Lisina em Ração de Lactação para Fêmeas Suínas Primíparas ${ }^{1}$
}

\section{Tereza da Silveira Cota ${ }^{2}$, Juarez Lopes Donzele ${ }^{3}$, Rita Flávia Miranda de Oliveira ${ }^{3}$, Darci Clementino Lopes $^{3}$, Uislei Antônio Dias Orlando ${ }^{4}$, Rafaela Antônia Ramos Generoso ${ }^{5}$}

\begin{abstract}
RESUMO - Foram utilizadas 40 porcas mestiças (Landrace x Large White) de primeiro parto, com peso médio de 182,2 $\pm 16,5 \mathrm{~kg}$ para avaliar diferentes níveis de lisina total $(0,95 ; 1,03 ; 1,10 ; 1,18 ;$ e 1,25\%) na ração, mantendo-se a mesma relação de aminoácidos, durante a lactação (21 dias). Utilizou-se o delineamento de blocos ao acaso com cinco tratamentos, oito repetições, sendo a porca considerada a unidade experimental. O consumo total de ração não variou entre os tratamentos, com as porcas consumindo, em média, 4,2 kg de ração por dia. O consumo de lisina e o peso das porcas à desmama aumentaram de forma linear, em razão do nível de lisina das rações. Embora a variação de peso das porcas não tenha sido significativa, as porcas que consumiram as rações com níveis de lisina iguais ou superiores a 1,18\% apresentaram menores valores absolutos de perda de peso durante a lactação. O ganho de peso e o peso à desmama dos leitões e da leitegada, a espessura de toucinho e o número de dias para a retomada do estro das porcas após a desmama não foram influenciados pelos níveis de lisina da ração. Concluiu-se que o nível de $0,95 \%$, correspondente a um consumo diário de $40 \mathrm{~g}$ de lisina total, atende às exigências de lisina de porcas primíparas em lactação.
\end{abstract}

Palavras-chave: consumo, desmame, estro, leitegada, porcas, reprodução

\section{Lysine Levels in the Diet of Primiparous Lactating Sows}

\begin{abstract}
Forty crossbred sows (Landrace x Large White) from the first parturition, with average weight of $182.2 \pm 16.5 \mathrm{~kg}$, were used to evaluate the total lysine levels $(0.95,1.03,1.10,1.18$, and $1.25 \%)$ in the diet, maintaining the same amino acids relation, during lactation (21 days). A completely randomized blocks design, with five treatments, eight replicates, where the sow was considered the experimental unit, was used. Total feed intake did not change according to the treatments, where the sows were daily fed, in average, $4.2 \mathrm{~kg}$. Lysine intake and sows weight at weaning linearly increased, according to the lysine levels in the diet. Although the sows weight variation was not significant, the sows fed diets with lysine levels equal or superior than $1.18 \%$ showed smaller absolute values of weight loss during lactation. Weight gain and weaning weight of piglets and litter, backfat thickness and the number of days to return to estrus of sows after weaning were not affected by the dietary lysine levels. It was concluded that the level of $0.95 \%$, correspondent to a daily intake of $40 \mathrm{~g}$ total lysine, met the lysine requirements of lactating primiparous sows.
\end{abstract}

Key Words: estrus, intake, litter, reproduction, sows, weaning

\section{Introdução}

Tem-se estabelecido em recentes trabalhos que porcas, principalmente de primeiro parto, perdendo quantidades excessivas de peso (proteína ou gordura), durante a lactação, apresentam maiores intervalos das duas coberturas, menores chances de entrar em estro dentro de dez dias após o desmame e menores taxas de parição e de sobrevivência dos embriões (Aherne \& Foxcroft, 2000), além de redução na taxa de gestação e diminuição do tamanho da leitegada subseqüente (Pettigrew, 1998), apresentando, por conseguinte, maiores índices de descarte.

Assim, torna-se de fundamental importância a determinação das exigências em nutrientes e energia, a fim de minimizar ou evitar a perda de peso das porcas em lactação. Entre os nutrientes exigidos pelos suínos, pode-se destacar a lisina, não somente pelo seu papel direto na formação da proteína exigida, mas também por ser considerada o primeiro aminoácido limitante para esses animais e utilizada como referência para a formulação de dietas.

Em tabelas elaboradas pelo NRC (1998), consta que porcas lactantes com $175 \mathrm{~kg}$, amamentando 10 leitões com ganho de peso médio durante a fase de aleitamento de $200 \mathrm{~g} /$ dia, em 21 dias de lactação, necessitam de $0,91 \%$ de lisina total na ração, o que corresponde a um nível de $0,79 \%$ de lisina digestível.

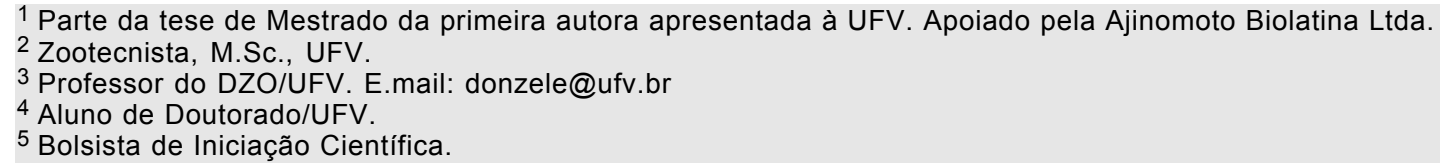


Altos níveis de ingestão de lisina digestível, da ordem de $45 \mathrm{a} 48 \mathrm{~g} / \mathrm{dia}$, têm sido usados para minimizar a mobilização de proteína corporal de porcas primíparas durante a lactação. Esses níveis de lisina digestível correspondem a níveis médios de 49 a $54 \mathrm{~g}$ /dia de lisina total (King et al., 1993; Touchette et al., 1998).

Tem-se verificado que a perda de peso total ao final da lactação é maior em porcas primíparas consumindo baixas quantidades de lisina (Richert et al., 1994; Jones \& Stahly, 1999a; Yang et al., 2000c), quando comparada com a perda de peso das fêmeas alimentadas com dietas que contêm altos níveis desse aminoácido na dieta e, associado a esse aumento na mobilização de reserva corporal (aumento da perda de peso), está o fato de as porcas não apresentarem diferença na variação de espessura de toucinho ao final da lactação.

O ganho de peso dos leitões e o número de leitões nascidos no segundo parto são variáveis importantes, quando se trata da quantidade de lisina ingerida por porcas de primeiro parto durante a lactação. A baixa ingestão de lisina pelas porcas durante a lactação, pode diminuir o ganho de peso da leitegada (King \& Dunkin, 1986; Richert et al., 1994; Jones \& Stahly, 1999a; Yang et al., 2000c) e o número de leitões nascidos no segundo parto (Touchette et al., 1998). Deve-se considerar, ainda, que porcas primíparas com inadequada ingestão de lisina, durante a lactação, podem ter seu desempenho reprodutivo subseqüente comprometido. Porcas primíparas consumindo baixo nível de lisina, mesmo quando associado a altos níveis de energia durante a lactação, retornaram ao estro mais tarde, apresentando redução na eficiência reprodutiva (Jones \& Stahly, 1999b; Tokach et al., 1992).

Com base nestas considerações, conduziu-se este estudo para determinar o melhor nível de lisina em rações de lactação para porcas de primeiro parto.

\section{Material e Métodos}

O experimento foi conduzido nas instalações da Granja de Melhoramento de Suínos da Universidade Federal de Viçosa.

Foram utilizadas 40 porcas mestiças (Landrace $\mathrm{x}$ Large White) de primeiro parto, com peso inicial médio após o parto de 182,2 $\pm 16,5 \mathrm{~kg}$. Foi utilizado o delineamento experimental em blocos ao acaso com cinco tratamentos $(0,95 ; 1,03 ; 1,10 ; 1,18 ;$ e $1,25 \%$ de lisina total na ração, mantendo-se a mesma relação de aminoácidos) e oito repetições, sendo cada porca considerada uma unidade experimental. As porcas foram distribuídas nos tratamentos de acordo com o peso inicial.

Durante a fase de gestação, as porcas receberam o mesmo manejo alimentar, ou seja: $1,8 \mathrm{~kg}$ de ração de gestação contendo $3,07 \mathrm{Mcal} / \mathrm{kg}$ de energia digestível (ED) e $15 \%$ de proteína bruta (PB) durante a primeira semana após cobertura; $2,2 \mathrm{~kg}$ de ração de gestação do $8^{\circ}$ ao $100^{\circ}$ dia de gestação; e $2,8 \mathrm{~kg}$ de ração de lactação (3,5 Mcal/kg de ED e $18,7 \%$ de $\mathrm{PB})$ do $101^{\circ}$ dia de gestação até o dia do parto.

Aos 107 dias de gestação, as marrãs foram transferidas do galpão de gestação para a sala de maternidade, onde permaneceram alojadas, individualmente, em gaiolas metálicas de dimensão de 2,20 x 1,40 $\mathrm{m}$, com comedouro do tipo cocho e bebedouro automático tipo concha. As gaiolas de parição foram providas de abrigo escamoteador com lâmpadas incandescentes, que se mantiveram acesas durante todo o período experimental, para aquecimento dos leitões.

A temperatura no interior das salas de maternidade foi monitorada diariamente durante todo o período experimental, três vezes ao dia (7h30, $11 \mathrm{~h} 30$ e $17 \mathrm{~h})$, por meio de termômetros de máxima e mínima, de bulbos seco e úmido e de globo negro. Os termômetros foram mantidos entre as gaiolas na altura correspondente à do corpo dos animais.

A composição centesimal e calculada das rações experimentais está apresentada na Tabela 1.

As rações experimentais foram formuladas à base de milho, farelo de soja e óleo de soja refinado, para atender às exigências de proteína bruta, conforme proposto pelo NRC (1998), para atender às necessidades de fêmeas com 10 leitões por leitegada com ganho de peso médio da leitegada de $200 \mathrm{~g} / \mathrm{dia}$. O nível de lisina, bem como os de metionina, treonina, triptofano e valina, por ser o objetivo desta pesquisa, variou de acordo com o tratamento e suas inclusões nas dietas foram em substituição ao inerte (caulim).

Para assegurar que a lisina fosse o primeiro aminoácido limitante nas rações, adotou-se o critério de manter os demais aminoácidos em um nível mínimo correspondente a $105 \%$ da relação com a lisina, conforme proposto pelo NRC (1998), com exceção dos aminoácidos valina e triptofano, cujas relações com a lisina corresponderam a 89 e $20 \%$ de lisina, respectivamente, conforme proposto por Carter et al. (2000), e das exigências de cálcio e fósforo, cujos valores 
utilizados foram os propostos por Rostagno (1996).

As rações foram fornecidas umedecidas em quantidade fixa de $4,5 \mathrm{~kg} /$ dia, em três refeições diárias, para assegurar um consumo de lisina total de 42,9; 46,$3 ; 49,7 ; 53,0 ;$ e $56,4 \mathrm{~g} /$ dia, nos cinco diferentes tratamentos. $\mathrm{O}$ acesso à água foi à vontade, em bebedouros automáticos tipo concha.

As porcas foram pesadas até 24 horas após o parto e a espessura de toucinho das mesmas foi mensurada no momento da pesagem, por meio de ultra-som, com duas medidas realizadas a $6,5 \mathrm{~cm}$ da linha dorsal à direita e à esquerda do animal, à altura da $10^{\text {a }}$ costela (P2), tomando-se como resultado a média das avaliações obtidas nos dois lados.

As porcas foram, novamente, pesadas e a espes- sura de toucinho, novamente, verificada no dia do desmame. Os leitões foram pesados até 24 horas após o nascimento e as leitegadas, padronizadas em nove ou dez leitões até o terceiro dia após o parto.

O leitão foi manejado (corte de dentes e cauda, cura do umbigo, marcação e administração de antibiótico) até 24 horas após o nascimento, aplicando-se ferro dextrano ao terceiro dia. Durante a lactação, os leitões não tiveram acesso à ração, mas tiveram água à vontade em bebedouros do tipo chupeta. Os leitões foram novamente pesados à desmama.

Após o desmame (21 dias), as fêmeas passaram a receber $3,0 \mathrm{~kg}$ de ração de lactação $(3,5 \mathrm{Mcal} / \mathrm{kg}$ de ED e $18,7 \%$ de proteína bruta), sendo verificada a retomada do estro, todos os dias, pela manhã, levando-

Tabela 1 - Composição centesimal e calculada das rações experimentais

Table 1 - Calculated composition of the experimental diets (\%)

\begin{tabular}{|c|c|c|c|c|c|}
\hline \multirow[t]{2}{*}{$\begin{array}{l}\text { Ingredientes }(\%) \\
\text { Ingredients }\end{array}$} & \multicolumn{5}{|c|}{$\begin{array}{c}\text { Níveis de lisina total na ração (\%) } \\
\text { Total lysine levels in the diets }\end{array}$} \\
\hline & 0,95 & 1,03 & 1,10 & 1,18 & 1,25 \\
\hline Milho moído (Ground corn) & 61,050 & 61,050 & 61,050 & 61,050 & 61,050 \\
\hline Farelo de soja (Soybean meal) & 27,510 & 27,510 & 27,510 & 27,510 & 27,510 \\
\hline Calcário calcítico (Limestone) & 0,635 & 0,635 & 0,635 & 0,635 & 0,635 \\
\hline Fosfato bicálcico (Dicalcium phosphate) & 2,520 & 2,520 & 2,520 & 2,520 & 2,520 \\
\hline L-lisina- $\mathrm{HCl}($ L-lysine- $\mathrm{HCl})$ & 0,000 & 0,095 & 0,191 & 0,287 & 0,382 \\
\hline DL-metionina (DL-methionine) & 0,000 & 0,000 & 0,014 & 0,056 & 0,098 \\
\hline L-treonina (L-threonine) & 0,000 & 0,019 & 0,071 & 0,122 & 0,174 \\
\hline L-triptofano (L-thryptophan) & 0,000 & 0,000 & 0,007 & 0,023 & 0,037 \\
\hline L-valina (L-valine) & 0,000 & 0,000 & 0,070 & 0,136 & 0,202 \\
\hline Inerte (caulim) & 0,925 & 0,811 & 0,572 & 0,301 & 0,032 \\
\hline Óleo vegetal (Vegetable oil) & 6,740 & 6,740 & 6,740 & 6,740 & 6,740 \\
\hline Mistura mineral ${ }^{1}$ (Mineral mix) & 0,100 & 0,100 & 0,100 & 0,100 & 0,100 \\
\hline Mistura vitamínica ${ }^{2}$ (Vitamin mix) & 0,100 & 0,100 & 0,100 & 0,100 & 0,100 \\
\hline Sal (Salt) & 0,410 & 0,410 & 0,410 & 0,410 & 0,410 \\
\hline BHT & 0,010 & 0,010 & 0,010 & 0,010 & 0,010 \\
\hline \multicolumn{6}{|l|}{ Composição calculada } \\
\hline \multicolumn{6}{|l|}{ Calculated composition } \\
\hline Energia metabolizável (Mcal/kg) (Metabolizable energy) & 3,46 & 3,46 & 3,46 & 3,46 & 3,46 \\
\hline Proteína bruta (Crude protein) $(\%)$ & 17,20 & 17,20 & 17,20 & 17,20 & 17,20 \\
\hline Lisina total (Total lysine) (\%) & 0,95 & 1,03 & 1,10 & 1,18 & 1,25 \\
\hline Lisina digestível (\%) (Digestible lysine) & 0,84 & 0,91 & 0,99 & 1,06 & 1,14 \\
\hline Metionina + cistina digestível $(\%)$ (Methionine + digestible cystine) & 0,529 & 0,529 & 0,543 & 0,585 & 0,626 \\
\hline Treonina digestível (\%) (Digestible threonine) & 0,602 & 0,621 & 0,672 & 0,722 & 0,774 \\
\hline Triptofano digestível (\%) (Digestible thryptophan) & 0,191 & 0,191 & 0,198 & 0,213 & 0,227 \\
\hline Valina digestível (\%) (Digestible valine) & 0,810 & 0,810 & 0,880 & 0,946 & 1,012 \\
\hline Cálcio (Calcium) $(\%)$ & 0,94 & 0,94 & 0,94 & 0,94 & 0,94 \\
\hline Fósforo total (Total phosphorus) (\%) & 0,74 & 0,74 & 0,74 & 0,74 & 0,74 \\
\hline Fósforo disponível (\%) (Available phosphorus) & 0,56 & 0,56 & 0,56 & 0,56 & 0,56 \\
\hline Sódio (Sodium) $(\%)$ & 0,20 & 0,20 & 0,20 & 0,20 & 0,20 \\
\hline
\end{tabular}

R. Bras. Zootec., v.32, n.1, p.115-122, 2003 
se a porca à baia do cachaço. Foram consideradas em estro as porcas que permaneceram imóveis à monta (reflexo de tolerância ao macho- RTM- positivo).

As análises de variância foram realizadas utilizando-se o programa ANOVAG, contido no pacote computacional SAEG 8.0 (Sistema para Análises Estatísticas e Genéticas). Os graus de liberdade para níveis de lisina foram desdobrados em polinômios ortogonais e as estimativas do melhor nível de lisina para porcas em fase de lactação, determinadas por meio de regressão linear ou quadrática, conforme melhor ajuste.

Para as análises de ganho de peso e peso ao desmame dos leitões e da leitegada, utilizaram-se como covariáveis, respectivamente, o peso dos leitões ao nascer e o peso da leitegada ao nascimento. Para análise de variação de espessura de toucinho, usou-se espessura de toucinho ao parto como covariável.

\section{Resultados e Discussão}

As médias das temperaturas observadas nos termômetros de bulbo seco (TBS) e bulbo úmido (TBU), temperaturas máxima (TMX) e mínima (TMN) e temperatura de globo negro (TGN), durante o período experimental, estão apresentadas na Tabela 2.

Considerando que a zona de termoneutralidade para porcas em lactação, segundo Nääs (2000), estaria caracterizada entre 12 e $25^{\circ} \mathrm{C}$, constatou-se, com base na variação de temperatura ocorrida durante a condução do experimento $\left(15,9\right.$ a $\left.27,6^{\circ} \mathrm{C}\right)$, que as porcas podem ter sido submetidas a períodos de estresse por calor, o que, provavelmente, pode ter influenciado os resultados de desempenho dos animais.

Os valores observados para consumos médio de ração diário na $1^{\mathrm{a}}, 2^{\mathrm{a}}$ e $3^{\mathrm{a}}$ semanas e total, consumos diários médios de lisina total e digestível e consumo de energia metabolizável médio diário das porcas durante o período de lactação estão apresentados na Tabela 3.

Não houve efeito $(\mathrm{P}>0,05)$ dos tratamentos sobre o consumo de ração médio diário, que foi de $4,2 \mathrm{~kg}$, o que estaria coerente com o fato de se ter fixado a quantidade de ração oferecida diariamente aos animais. Embora a quantidade de ração oferecida às porcas tenha sido igual nos diferentes tratamentos, os animais não alcançaram o consumo total pré-determinado de $4,5 \mathrm{~kg} /$ dia de ração, uma vez que a maioria das fêmeas não atingiu este consumo durante a primeira semana de lactação.

Comportamento semelhante de consumo de ração, em porcas de primeiro parto, foi observado por
Tabela 2 - Valores médios das temperaturas dos termômetros de máxima (TMX) e mínima (TMN), de bulbo seco (TBS) e bulbo úmido (TBU) e temperatura média do globo negro (TGN) e seus respectivos desvios-padrão medidos durante o período experimental

Table 2 - Average temperatures values of maximum (TMX) and minimum (TMN) thermometers, dry bulb (TBS) and humid bulb (TBU) and average temperature of black globe (TGN) and its respective standard deviations, measured during the experimental period

\begin{tabular}{|c|c|c|c|c|}
\hline \multicolumn{4}{|c|}{$\begin{array}{c}\text { Temperaturas }\left({ }^{\circ} \mathrm{C}\right) \\
\text { Temperatures }\end{array}$} & \multirow{2}{*}{$\begin{array}{c}\begin{array}{c}\text { Índice } \\
\text { Index }\end{array} \\
\text { TGN }\end{array}$} \\
\hline TMX & $\mathrm{TMN}$ & TBS & TBU & \\
\hline $27,6 \pm 3,28$ & $15,9 \pm 3,15$ & $21,9 \pm 2,53$ & $18,8 \pm 1,83$ & $23 \pm 2,77$ \\
\hline
\end{tabular}

Tokach et al. (1992), que, estudando níveis de energia e lisina, observaram consumo inferior ao proposto durante a primeira semana de lactação.

Os estresses de parto e de calor, ocorridos durante o período experimental, possivelmente, foram fatores que contribuíram para que o patamar de consumo diário de 4,5 kg de ração não fosse atingido antes da primeira semana de lactação.

O consumo de lisina total aumentou de forma linear $(\mathrm{P}<0,05)$, segundo a equação $\hat{Y}=37,028+$ $3,13932 \times\left(r^{2}=0,98\right)$, em função da elevação do nível de lisina na ração. Como o consumo de ração não variou significativamente entre os tratamentos, o aumento no consumo de lisina total ocorreu em razão direta de sua concentração nas rações. Já o consumo de energia metabolizável, que foi, em média, de 14,5 Mcal/dia, não variou $(\mathrm{P}>0,05)$ entre os tratamentos, $\mathrm{o}$ que pode ser explicado pelo fato das rações terem sido isoenergéticas e do consumo total de ração pelas porcas ter sido semelhante.

Os resultados de desempenho das porcas durante o período de lactação encontram-se na Tabela 4.

O peso das porcas no final da lactação aumentou de forma linear $(\mathrm{P}<0,05)$, segundo a equação $\hat{Y}=173,377+1,7925 \mathrm{X}\left(\mathrm{r}^{2}=0,62\right)$, em função da concentração de lisina da ração e, conseqüentemente, do aumento no consumo de lisina. Como o peso das porcas pós-parto não diferiu $(\mathrm{P}>0,05)$ entre os tratamentos, pode-se inferir que a condição corporal da porca, na lactação, melhorou com o aumento do consumo de lisina.

Resultados semelhantes foram observados por Jones \& Stahly (1999b), que, trabalhando com dois níveis de lisina $(0,34$ e 1,20\%), durante o período de 
lactação, também observaram relação positiva entre o aumento do nível de lisina da ração e o peso das porcas no final da lactação.

A perda de peso das fêmeas durante a lactação não foi influenciada $(\mathrm{P}>0,05)$ pelo nível de lisina da ração. Resultados semelhantes foram obtidos por Lewis \& Spencer (1973), King et al. (1993), Knabe et al. (1996) e Yang etal. (2000b), que também não encontraram diferença na variação de peso das fê- meas, em função do consumo de lisina, quando estes variaram entre 0,25 e $1,6 \%$, durante a lactação.

Por outro lado, King \& Martin (1989), Richert et al. (1994), Jones \& Stahly (1999a) e Yang et al. (2000b) constataram maior perda de peso total ao final da lactação em porcas de primeiro parto, quando estas consumiram rações com baixos níveis de lisina comparadas com as alimentadas com rações contendo altos níveis desse aminoácido. A diferença de resulta-

Tabela 3 - Consumo de ração, de lisina total e digestível e de energia das fêmeas, durante o período de lactação

Table 3 - Feed intake, total and digestible lysine and energy intakes of gilts during the lactation period

\begin{tabular}{|c|c|c|c|c|c|c|}
\hline \multirow[t]{2}{*}{$\begin{array}{l}\text { Variáveis } \\
\text { Variables }\end{array}$} & \multicolumn{5}{|c|}{$\begin{array}{c}\text { Níveis de lisina da ração (\%) } \\
\text { Lysine levels in the diets }\end{array}$} & \multirow[t]{2}{*}{$\mathrm{CV}(\%)$} \\
\hline & 0,95 & 1,03 & 1,10 & 1,18 & 1,25 & \\
\hline \multicolumn{7}{|l|}{ Consumo de ração, kg/dia } \\
\hline \multicolumn{7}{|l|}{ Feed intake } \\
\hline $1^{\mathrm{a}}$ semana $\left(1^{s t}\right.$ week $)$ & 3,6 & 3,8 & 3,8 & 3,9 & 3,5 & \\
\hline $2^{\mathrm{a}}$ semana $\left(2^{\text {nd }}\right.$ week $)$ & 4,5 & 4,5 & 4,5 & 4,5 & 4,5 & \\
\hline $3^{\mathrm{a}}$ semana $\left(3^{r d}\right.$ week $)$ & 4,5 & 4,5 & 4,5 & 4,5 & 4,5 & \\
\hline Consumo total de ração, $\mathrm{kg} / \mathrm{dia}$ & 4,2 & 4,25 & 4,25 & 4,3 & 4,15 & 5,03 \\
\hline Total feed intake & & & & & & \\
\hline $\begin{array}{l}\text { Consumo de lisina total, } \mathrm{g} / \mathrm{dia}^{1} \\
\text { Total lysine intake }\end{array}$ & 39,9 & 43,8 & 46,75 & 50,75 & 52,0 & 5,23 \\
\hline $\begin{array}{l}\text { Consumo de lisina digestível, } \mathrm{g} / \mathrm{dia}^{1} \\
\text { Digestible lysine intake }\end{array}$ & 35,3 & 38,7 & 42,0 & 45,6 & 47,3 & 5,25 \\
\hline $\begin{array}{l}\text { Consumo de energia, Mcal/dia de EM } \\
\text { Energy intake }\end{array}$ & 14,5 & 14,7 & 14,7 & 14,9 & 14,4 & 5,03 \\
\hline
\end{tabular}

${ }^{1}$ Efeito linear $(P<0,05)$ Linear effect $(P<0.05)$.

Tabela 4 - Peso e variação de peso, espessura de toucinho e variação de espessura de toucinho e intervalo desmamaestro das porcas durante a lactação, de acordo com o nível de lisina da ração

Table 4 - Weight and weight change, backfat thickness and backfat thickness variation and weaning-estrus interval of sows during lactation, according to the lysine levels in the diet

\begin{tabular}{|c|c|c|c|c|c|c|}
\hline \multirow{2}{*}{$\begin{array}{l}\text { Variáveis } \\
\text { Variables }\end{array}$} & \multicolumn{5}{|c|}{$\begin{array}{c}\text { Níveis de lisina da ração (\%) } \\
\text { Lysine levels in the diets }\end{array}$} & \multirow[t]{2}{*}{$\mathrm{CV}(\%)$} \\
\hline & 0,95 & 1,03 & 1,10 & 1,18 & 1,25 & \\
\hline Número de animais (Number of animals) & 8 & 8 & 8 & 8 & 8 & \\
\hline \multicolumn{7}{|l|}{ Peso da porca (kg) (Gilt weight) } \\
\hline Pós-parto (Post-partum) & 181 & 181 & 183 & 182 & 184 & 2,23 \\
\hline À desmama ${ }^{1}$ (At weaning) & 178 & 174 & 178 & 180 & 183 & 3,9 \\
\hline Variação de peso (kg) (Weight change) & -3 & -7 & -5 & -2 & -1 & 166 \\
\hline Variação de peso relativa (\%) (Relative weight change) & 1,7 & 3,9 & 2,7 & 1,1 & 1,0 & \\
\hline \multicolumn{7}{|l|}{ Espessura de toucinho (mm) (Backfat thickness) } \\
\hline Pós-parto (Post-partum) & 16,6 & 15,0 & 15,0 & 19,25 & 17,0 & 22,2 \\
\hline À desmama (At weaning) & 15,3 & 13,3 & 13,4 & 17,5 & 15,4 & \\
\hline Variação na ET (mm) (Change in BT) & $-1,3$ & $-1,7$ & $-1,6$ & $-1,7$ & $-1,6$ & 76,7 \\
\hline Intervalo desmama-estro, dias (Weaning-estrus interval, days) & 5,6 & 5,3 & 5,0 & 4,6 & 5,1 & 21,6 \\
\hline
\end{tabular}

${ }^{1}$ Efeito linear $(P<0,05)$.

${ }^{1}$ Linear effect $(P<.05)$.

R. Bras. Zootec., v.32, n.1, p.115-122, 2003 
dos observada entre as pesquisas pode estar relacionada ao fato de que os autores acima referenciados avaliaram somente dois ou três níveis de lisina, com diferença mínima de $0,40 \%$ entre eles; enquanto neste estudo foram avaliados cinco níveis com diferença máxima de $0,30 \%$ entre os níveis extremos avaliados.

Comparando os resultados obtidos no presente estudo com os apresentados por Touchette et al. (1998), que constataram variação significativa de $52 \%$ na perda de peso de porcas primíparas em lactação (59 animais/tratamento) consumindo diferentes níveis de lisina digestível na ração $(0,67$ a $1,25 \%)$, pode-se inferir que o baixo número de repetições utilizado neste estudo (08), evidenciado pelo alto coeficiente de variação (166) para essa variável, provavelmente, tenha sido o fator responsável para que a variação de $87,5 \%$ na perda de peso das porcas em lactação, entre os tratamentos, não tenha sido significativa.

Embora não tenha sido observado efeito dos tratamentos sobre a variação de peso das porcas primíparas durante a lactação, as porcas que consumiram ração com níveis de lisina iguais ou superiores a $1,18 \%$, correspondente a um consumo diário de $50,8 \mathrm{~g}$ de lisina total, apresentaram menores valores absolutos de perda de peso. Assim, pode-se inferir que o consumo de lisina diário na lactação, possivelmente, constitui um dos fatores que influencia a mobilização de reserva corporal das porcas para manter a produção de leite.

Com relação à perda de peso das porcas durante a lactação, foi constatada correlação linear positiva $(\mathrm{r}=0,5467 ; \mathrm{P}<0,05)$, expressa pela equação $\hat{Y}=-37,3092+0,223572 \mathrm{X}$, entre a perda de peso das porcas na lactação em função do peso após o parto. Estes resultados estão em acordo com os relatados por Whittemore (1996), onde porcas mais pesadas ao parto perdem mais peso durante a lactação.

A variação da espessura de toucinho (ET) das porcas durante a lactação não foi influenciada $(\mathrm{P}>0,05)$ pelos tratamentos. Estes resultados foram similares aos obtidos por vários autores (King \& Martin, 1989; Johnston et al., 1993; Richert et al., 1994; Sauber et al., 1998; Touchette et al., 1998; Jones \& Stahly, 1999a; Yang et al., 2000c), que, avaliando níveis de lisina para porcas em lactação, também não verificaram variação na ET dos animais na lactação. Por outro lado, Yang et al. (2000b) constataram variação significativa na ET das porcas durante a fase de lactação, tendo esta diminuído, de forma linear, à medida que se elevou o nível de lisina na ração de 0,6 a 1,6\%.

Considerando a variação de peso das porcas ocorrida durante a lactação, pode-se inferir que, provavelmente, a medida de espessura de toucinho não tenha sido o parâmetro adequado para se avaliar a variação da composição corporal da porca com relação à mobilização total de gordura.

Em estudos conduzidos por Sauber et al. (1998) e Jones \& Stahly (1999a), ficou também evidenciado que a medida de ET não refletiu a variação na condição corporal de porcas primíparas recebendo diferentes níveis de lisina na ração durante a lactação, uma vez que esses autores constataram que a variação na mobilização de gordura corporal das porcas, entre os tratamentos, não foi detectada pela medição na espessura de toucinho, mesmo tendo sido avaliada em diferentes pontos no animal.

Não houve alteração $(\mathrm{P}>0,05)$ no número de dias para a retomada do estro das porcas após o desmame, em função dos níveis de lisina da ração. De forma semelhante, Touchette et al. (1998) também não verificaram influência do consumo de lisina (32 a $59 \mathrm{~g} /$ dia) de porcas primíparas na lactação sobre o intervalo desmama-estro. No entanto, Jones \& Stahly (1999b), avaliando níveis baixo $(0,34 \%)$ e alto $(1,2 \%)$ de lisina, correspondentes aos consumos diários respectivos de 16,2 e $58,9 \mathrm{~g}$ /dia durante a lactação, verificaram maior intervalo desmama-estro nas porcas que receberam ração com baixo nível de lisina. Esses autores relataram, ainda, que a menor secreção de LH no $10^{\circ}$ dia após o parto, das porcas que apresentaram baixo consumo de lisina, teria sido o fator determinante para o aumento no intervalo desmama-estro desses animais.

Considerando os relatos de King \& Martin (1989), Jones \& Stahly (1999b) e Yang et al. (2000a), de que a variação no intervalo desmama-estro, em função do nível de lisina da ração, estaria relacionada com a secreção pulsátil de LH durante a lactação e após a desmama, é possível deduzir que as diferenças observadas no consumo de lisina total (de 39,9 a 50,8 g/dia) entre os tratamentos, no presente estudo, não foram suficientes para influenciar o padrão de secreção de LH das porcas e, conseqüentemente, o número de dias para o aparecimento do estro após a desmama.

Os resultados obtidos no presente estudo estão em acordo com a conclusão de Yang et al. (2000b) de que o consumo de lisina acima de um nível crítico mínimo de ingestão, correspondente a $35 \mathrm{~g} /$ dia, não resulta em diminuição no intervalo desmama-estro para porcas primíparas.

O número de dias médio para o retorno ao estro das 
porcas após a desmama de 5,1 dias, observado no presente estudo, ficou abaixo da média de 10,3 dias ocorrida em diversos estudos, em que se avaliaram níveis de lisina para porcas primíparas em lactação (King \& Dunkin, 1986; Knabe et al., 1996; Touchette et al., 1998; Jones \& Stahly, 1999b; Yang et al., 2000b), e também foi inferior à de sete dias referenciada por Silveira et al. (1998) como número médio para as porcas retornarem ao estro após a desmama.

Em relação, ainda, à retomada do estro pelas porcas após a desmama, observou-se correlação linear positiva $(\hat{Y}=4,94812+0,0467238 \mathrm{X}, \mathrm{r}=0,2782 \mathrm{X} ; \mathrm{P}<0,05)$ entre o número de dias para a retomada do estro após a desmama e a perda de peso das fêmeas durante a lactação. As porcas que retornaram ao estro em intervalo inferior a seis dias apresentaram perda de peso corporal média de $1,18 \mathrm{~kg}$, enquanto as que levaram mais de seis dias para apresentarem estro perderam, em média, 8,19 kg. Estes resultados foram similares aos obtidos por Tokach et al. (1992), que observaram maior intervalo desmama-estro nas porcas primíparas que perderam mais peso durante a lactação.

Os resultados de ganho de peso dos leitões e da leitegada durante o período de lactação estão apresentados na Tabela 5.

Como se utilizou o critério de equalizar o tamanho das leitegadas das porcas após o parto, não se observou variação $(\mathrm{P}>0,05)$ neste parâmetro entre os tratamentos. A padronização da leitegada neste estudo pode ser justificada pelo fato de que o número de leitões na leitegada tem influência sobre a produção de leite e, conseqüentemente, sobre a exigência nutricional da porca. Kim et al. (1999) concluíram que a exigência de lisina de porcas primíparas em lactação é aumenta- da em $0,96 \mathrm{~g} /$ dia para cada leitão a mais na leitegada.

Não houve correlação $(\mathrm{P}>0,05)$ entre o tamanho da leitegada e a variação de peso da porca durante a lactação, nem entre o tamanho da leitegada e a variação na espessura de toucinho das porcas $(\mathrm{P}>0,05)$. Dessa forma, pode-se deduzir que a variação não-significativa de até 0,6 leitões nas leitegadas entre os tratamentos não influiu na variação de peso corporal e de espessura de toucinho das porcas durante a lactação.

$\mathrm{O}$ peso à desmama e o ganho de peso dos leitões e da leitegada não foram influenciados $(\mathrm{P}>0,05)$ pelo aumento do consumo de lisina das porcas na lactação. Dourmand et al. (1998) e Touchette et al. (1998) também não observaram influência do consumo de lisina das porcas primíparas em lactação, de 27,5 a $59 \mathrm{~g} /$ dia, sobre a variação de peso da leitegada. No entanto, Yang et al. (2000c), avaliando níveis baixo $(0,4 \%)$, médio $(1,0 \%)$ e alto $(1,6 \%)$ de lisina em rações de porcas primíparas em lactação, observaram menor ganho de peso da leitegada das porcas que receberam baixo nível de lisina, em consumo correspondente a $16 \mathrm{~g} / \mathrm{dia}$, não obstante, Jones \& Stahly (1999b) observaram maior ganho de peso da leitegada de porcas que consumiram 58,9 g/dia de lisina na lactação, em relação às que consumiram 16,2 g/dia.

Assim, pode-se inferir que somente com consumo diário de lisina abaixo de $27 \mathrm{~g} /$ dia é possível constatar influencia do teor de lisina sobre o ganho se peso da leitegada.

O valor médio de $188 \mathrm{~g}$ de ganho de peso diário dos leitões durante a lactação ficou próximo ao valor médio de 196,5 g/dia obtido por Dourmand et al. (1998), que também trabalharam com porcas de

Tabela 5 - Desempenho da leitegada equalizada, durante a lactação, de acordo com o nível de lisina da ração Table 5 - Performance of equalized litter, during lactation, according to the lysine level in the diet

\begin{tabular}{|c|c|c|c|c|c|c|}
\hline \multirow[t]{2}{*}{$\begin{array}{l}\text { Variáveis } \\
\text { Variables }\end{array}$} & \multicolumn{5}{|c|}{$\begin{array}{c}\text { Níveis de lisina da ração (\%) } \\
\text { Lysine levels in the diets }\end{array}$} & \multirow[t]{2}{*}{$\mathrm{CV}(\%)$} \\
\hline & 0,95 & 1,03 & 1,10 & 1,18 & 1,25 & \\
\hline Número de leitões (Number of piglets) & 9,7 & 9,3 & 9,1 & 9,1 & 9,3 & 7,38 \\
\hline \multicolumn{7}{|l|}{ Peso da leitegada (Litter weight) } \\
\hline Ao nascer, $\mathrm{kg}$ (At birth) & 13,25 & 13,05 & 13,12 & 12,67 & 12,90 & \\
\hline Ao desmame, $\mathrm{kg}$ (At weaning) & 51,86 & 52,26 & 46,31 & 46,39 & 51,98 & 11,6 \\
\hline Ganho de peso, $\mathrm{kg}$ (Weight gain) & 38,61 & 39,21 & 33,19 & 33,72 & 39,08 & 15,6 \\
\hline \multicolumn{7}{|l|}{ Peso dos leitões, kg (Piglets weight) } \\
\hline Ao nascer (At birth) & 1,37 & 1,40 & 1,44 & 1,39 & 1,39 & \\
\hline Ao desmame (At weaning) & 5,37 & 5,67 & 5,10 & 5,10 & 5,60 & 11,7 \\
\hline Ganho de peso (Weight gain) & 4,00 & 4,24 & 3,66 & 3,71 & 4,21 & 15,9 \\
\hline Ganho de peso, g/dia (Weight gain) & 190 & 203 & 174 & 176 & $199^{2}$ & 15,9 \\
\hline
\end{tabular}

R. Bras. Zootec., v.32, n.1, p.115-122, 2003 
primeiro parto com período de lactação de 21 dias, e foi superior à média de $174 \mathrm{~g} /$ dia encontrada por Yang et al. (2000c), que trabalharam com porcas primíparas por 18 dias de lactação.

\section{Conclusões}

O nível de $0,95 \%$ de lisina total, correspondente a um consumo de $40 \mathrm{~g} / \mathrm{dia}$, atende às exigências nutricionais de porcas primíparas em lactação.

\section{Literatura Citada}

AHERNE, F.; FOXCROFT,G. Manejo da leitoa e da porca primípara: parte $\mathrm{V}$. manejo nutricional na gestação e lactação. In: SIMPÓSIO INTERNACIONAL DE REPRODUÇÃO E INSEMINAÇÃO ARTIFICIAL EM SUÍNOS, 7., 2000, Foz do Iguaçu, PR. Anais... Foz do Iguaçu. 2000. p.145-165.

CARTER, S.D.; HILL, G.M.; MAHAN, D.C. et al. Effects of dietary valine concentration on lactational performance of sows nursing large litters. Journal of Animal Science, v.78, p.2879-2884, 2000.

DOURMOND, J.Y.; NOBLET, J.; ÉTIENE, M. Effect of protein and lysine supply on performence, nitrogen balance, and body composition changes of sows during lactation. Journal of Animal Science, v.76, p.542-550, 1998.

JONES, D.B.; STAHLY, T.S. Impact of amino acid nutrition during lactation on luteinizing hormone secretion and return to estrus in primiparous sows. Journal of Animal Science, v.77, p.5231531, 1999a.

JONES, D.B.; STAHLY, T.S. Impact of amino acid nutrition during lactation on body nutrient mobilization and milk nutrient output in primiparous sows. Journal of Animal Science, v.77, p.1513-1522, 1999 b.

JOHnston, L.J.; PETTIGREW, J.E.; RUST, J.W. Response of maternal-line sows to dietary protein concentration during lactation. Journal of Animal Science, v.71, p.2152-2156, 1993.

KIM, S.W.; OSAKA, I.; HURLEY, W.L. et al. Mammary gland growth as influenced by litter size in lactating sows: impact on lysine requirement. Journal of Animal Science, v.77, p.3316-3321, 1999.

KING, R.H.;. DUNKIN, A.C. The effect of nutrition on the reproductive performance of first-litter sows. Animal Production, v.43, p.319-325, 1986.

KING., R.H.; LE DIVIDICH, J.; DUNSHEA, F.R. Lactation and neonatal growth. In: KYRIAZAKIS, I. (Ed.) A quantitative biology of the pigs. London, 1999. p.155-180.

KING, R.H.; MARTIN, G.B. Relationship between protein intake during lactation, LH levels and oestrous activity in first-litter sow. Animal Reproduction Science, v. 19, p.283292, 1989.

KING, R.H.; TONER, M.S.; DOVE, H. et al. The response of first-litter sows to dietary level during lactation. Journal of Animal Science, v.71, p.2457-2463, 1993.

KNABE, D.A.; BRENDEMUHL, J.H.; CHIBA, L.I. et al. Supplemental lysine for sows nursing large litters. Journal of Animal Science, v.74, p.1635-1640, 1996.

LEWIS, A.J.; SPEER, V.C. Lysine requirement of the lactating sow. Journal of Animal Science, v.1, p.104-110, 1973.

R. Bras. Zootec., v.32, n.1, p.115-122, 2003
MAFFILI, V.V. Fatores que afetam a eficiência reprodutiva de rebanhos suínos. Viçosa, MG: Universidade Federal de Viçosa, 2000. Dissertação (Mestrado em Veterinária) Universidade Federal de Viçosa, 2000.

NÄÄS, I.A. Influência do ambiente na resposta reprodutiva de fêmeas. In: SIMPÓSIO INTERNACIONAL DE REPRODUÇÃO E INSEMINAÇÃO ARTIFICIAL EM SUÍNOS, 7., 2000, Foz do Iguaçu. Anais... Foz do Iguaçu. 2000. p. 253-262.

NATIONAL RESEARCH COUNCIL. - NRC. Nutrient requirements of swine. 10.ed. Washington, D.C.: National Academic Science, Committee Animal Nutrition. Subcommittee of Swine Nutrition, 1998. 189p.

PETTIGREW, J.E. Nutrition and prolificacy. In: IPVS CONGRESS, 15., Birmingham, U.K., 1998. Proceedings... Birmingham, 1998. p.319-323.

RICHERT, B.T.; GOODBAND, R.D.; TOKACH, M.D. et al. The effect of lysine and valine fed during lactation on sow and litter lactation performance. Swine Day, p.19-23, 1994.

ROSTAGNO, H.S. In: SIMPÓSIO INTERNACIONAL SOBRE EXIGÊNCIAS NUTRICIONAIS DE AVES E SUÍNOS, 1996, Viçosa, MG, 1996. Anais... Viçosa: Universidade Federal de Viçosa, 1996.

SAUBER, T.E.; STAHLY, T.S.; WILLIAMS, N.H. et al. Effect of lean growth genotype and dietary amino acid regime on lactational performance of sows. Journal of Animal Science, v.76, p.1098-1111, 1998.

SILVEIRA, P.R.S; BORTOLOZZO, F.; WENTZ, I. et al. Manejo da fêmea reprodutora. In: SOBESTIANSKY, I.; WENTZ, I.; SILVEIRA, L. (Eds.) Suinocultura intensiva - Produção, manejo e saúde do rebanho. 2.ed. Brasília, 1998. p.163-196.

TOKACH, M.D.; PETTIGREW, J.E.; DIAL, G.D. et al. Characterization of luteinizing hormone secretion in the primiparous, lactating sow: relationship to blood metabolites and return-to-estrus interval. Journal of Animal Science, v.70, p.2195-2201, 1992.

TOUCHETTE, K.J.; ALLEE, G.L.; NEWCOMB, M.D. et al. The lysine requirement of lactating primiparous sows. Journal of Animal Science, v.76, p.1091-1097, 1998.

YANG, H., FOXCROFT, G.R.; PETTIGREW, J.E. et al. Impact of dietary lysine intake during lactation on follicular development and oocyte maturation after weaning in primiparous sows. Journal of Animal Science, v.78, p.993-1000. 2000a.

YANG, H.; PETTIGREW, J.E.; JOHNSTON, L.J. et al. Lactational and subsequent reproductive responses of lactating sows to dietary lysine (protein) concentration. Journal of Animal Science, v.78, p.348-357, 2000b.

YANG, H.; PETTIGREW, J.E.; JOHNSTON, L.J. et al. Effects of dietary lysine intake during lactation on blood metabolites hormones, and reproductive performance in primiparous sows. Journal of Animal Science, v.78, p.1001-1009, 2000c.

WHITTEMORE, C.T. Nutrition reproduction interaction in primiparous sows. Livestock Production Science, v.46, p.65-83, 1996.
Recebido em: 21/06/02 Aceito em: 10/10/02 